\title{
Application of Synchrotron Spectroscopy to Understanding Gold Mineralization at the Monument Bay Project, Stull Lake Greenstone Belt, Manitoba, Canada
}

\author{
Hannah E. Cavallin ${ }^{1}$, Neil R. Banerjee ${ }^{2 *}$ and Lisa L Van Loon ${ }^{2,3}$ \\ 1. Yamana Gold Inc., Toronto, ON, Canada. \\ 2. Department of Earth Sciences, Western University, London, ON, Canada. \\ 3. LISA CAN Analytical Solutions Inc., Saskatoon, SK, Canada. \\ * Corresponding author: neil.banerjee@uwo.ca
}

The Monument Bay Project consists of economically promising Archean shear-hosted gold-tungsten deposits located approximately $570 \mathrm{~km}$ northeast of Winnipeg, Manitoba. The property is located within the Oxford Stull Domain of the Western Superior Province in the east-west-trending Stull Lake Greenstone Belt exposed across northeastern Manitoba and northwestern Ontario. The project area comprises three significant gold occurrences: The Twin Lakes deposit, the Mid-East Zone, and the AZ showing. All three are located along strike of major east-trending, steeply north-dipping shear zones intruded by quartz-feldspar porphyry units in the west. Early, regional silicification and pervasive sericite alteration aureoles that extend parallel to shear strike created anisotropy in the host metavolcanics and metasediments. This rock preparation provided an ideal rheologic competency contrast for transition between ductile and brittle deformation, consequent and penecontemporaneous alteration, and ultimately, gold mineralization.

Synchrotron micro X-Ray Fluorescence (SR- $\mu \mathrm{XRF)}$ provides rapid, high-resolution trace element mapping in ore minerals to identify elemental correlations with gold, arsenic, and tungsten (scheelite). This integration of geochemical information with mineralogical and spatial context provides a new framework for investigating mineralizing fluids and an opportunity for the development of innovative exploration vectors that link multi-stage exploration data analysis with petrography and can be directly transferred to observations in drill core in the field.

Select samples prepared as thin sections were examined by petrographic analysis to identify major and accessory mineral phases, mineralized textures, structures, alteration assemblages, and ore mineralogy. The corresponding thin section offcut billets and quarter core were analysed by SR- $\mu$ XRF at the IDEAS beamline at the Canadian Light Source (CLS) in Saskatoon, SK to create 2D trace element maps that reveal spatial and structural associations with gold mineralization. The incident X-ray energy was set to $13750 \mathrm{eV}$. A Ketek ${ }^{\circledR}$ AXAS-M single element SDD was used to measure the XRF signal. SR-XRF mapping was done by rastering across the sample in both directions with a beam spot size of $500 \mu \mathrm{m} \mathrm{x}$ $500 \mu \mathrm{m}$ and a dwell time of $1 \mathrm{sec}$. The distance between the sample and the detector was set to $8 \mathrm{~cm}$ for all samples. SR-XRF data analysis was done with Peakaboo 4 [1]. SR-PXRD data collection on corresponding pulp rejects was conducted at the CMCF beamline 08BM-1 following the established setup and parameters for geologic materials [2]. Phase analysis was performed using Bruker's EVA software [3] with the PDF-2001 database.

Extensive geochemical data analysis, petrography, SR-PXRD, and SR- $\mu$ XRF mapping, determined that gold occurs predominantly as randomly dispersed micron-scale blebs of free gold associated with corroded and sieve-textured pyrite and arsenopyrite and as inclusions within coarse pyrite grains. The SR-uXRF maps show gold commonly occurs closely associated with As and W, both independently and 
together. Scheelite mineralization is not directly linked to the presence of gold, but may indicate conduits for late, hot mineralizing fluids responsible for high-grade gold deposition. Fluids responsible for sericite alteration along the shear zone may have carried early generations of sulfide minerals and gold and could potentially provide a mineralogical pathfinder to mineralization. Brecciated, silicified, and healed mineralized shear material occurring throughout the deposits at Monument Bay demonstrate a long-lived, multi- episodic fluid history, and varied textures observed in sulfide minerals point to multiple fluid generations and potential fluid mixing [4].

References:

[1] N Sherry et al, Science Studio Project Summary (2012). http://sciencestudio.net/summary.php.

[2] N Flynn et al., Microsc. Microanal. 24(S2) (2018), p. 518.

[3] Bruker Corporation, EVA Software, www.bruker.com.

[4] Research described in this paper was performed at the Canadian Light Source, which is supported by the CFI, NSERC, the Univ. of Saskatchewan, the Government of Saskatchewan, Western Economic Diversification Canada, the NRC, and the CIHR. The authors acknowledge funding from NSERC and Yamana Gold Inc. We thank D. Muir, M. Fodje, and S. Labiuk for support in conducting the experiments.

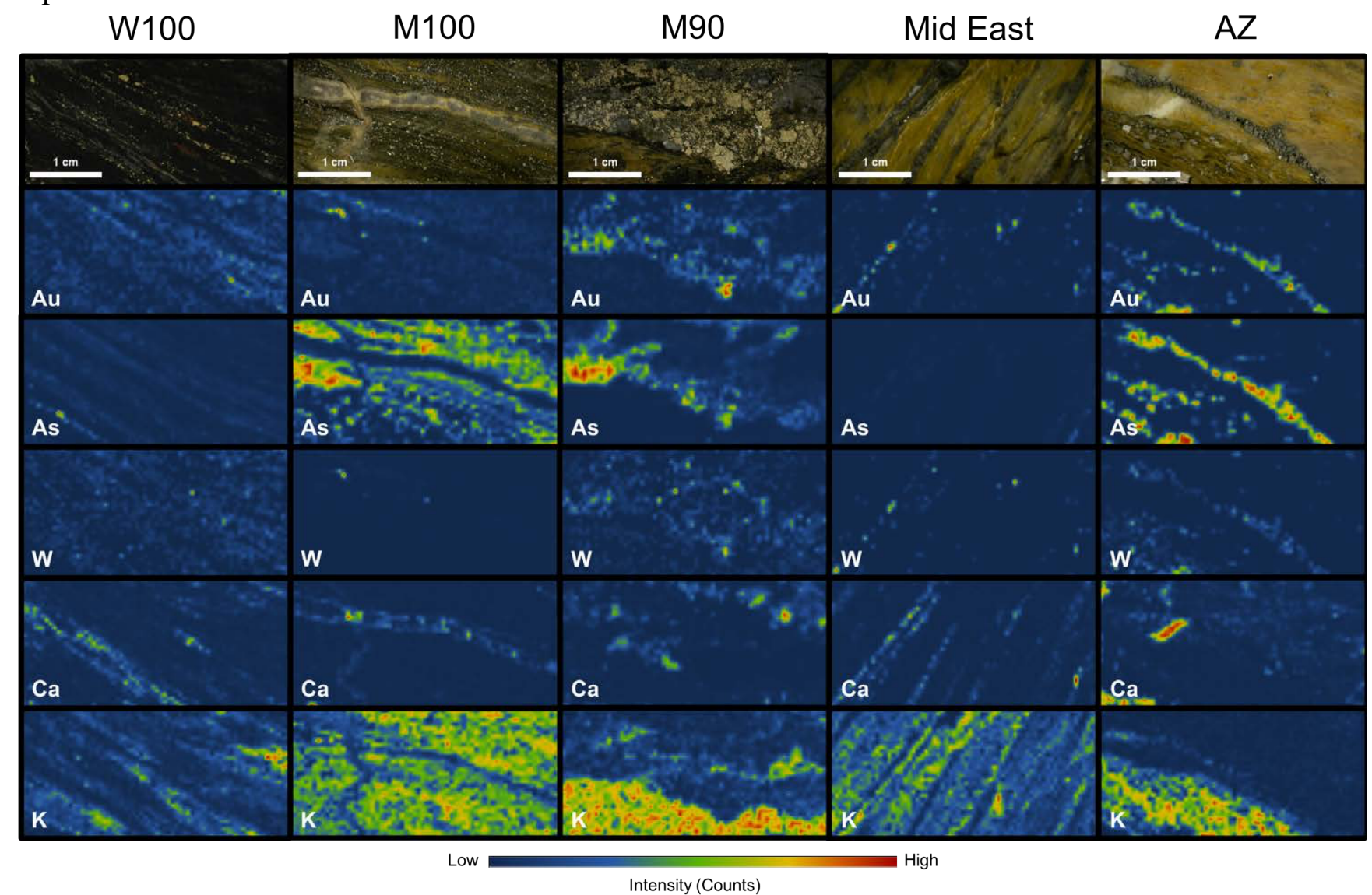

Figure 1. SR $-\mu \mathrm{XRF}$ trace element "Map Stacks" showing elements associated with gold mineralization and alteration for samples across the zones of Twin Lakes, as well as for the Mid-East and AZ deposits. 